\title{
Measurement and Experimental Testing of Models for the Estimation of HourlySolar Radiation on Vertical Surfaces at Mexico City
}

\author{
Liliana Y. Maldonado Sánchez ${ }^{1 *}$, Mauro Valdés Barrón ${ }^{2}$, Jesús Polo Martínez $^{3}$, Nuria Martín Chivelet ${ }^{3}$ \\ ${ }^{1}$ Master and PhD Program in Architecture, National Autonomous University of Mexico(UNAM), Circuito de Posgrados, Cd. Universita- \\ ria, Coyoacán, 04510, Ciudad de México, Mexico. \\ ${ }^{2}$ Geophysics Institute, National Autonomous University of Mexico (UNAM), Circuito de la investigación Científica s/ $n$, Ciudad Univer- \\ sitaria, Coyoacán, 04510, Ciudad de México, Mexico \\ ${ }^{3}$ Photovoltaic Solar Energy Unit (Renewable Energy Division, CIEMAT), Av. Complutense, 40, 28040 Madrid, Spain \\ *Corresponding author E-mail: lyms.maldonado@gmail.com
}

\begin{abstract}
This paper presents the results of measuring global solar irradiation in horizontal and vertical surfaces North, South, East and West with the aim to determine the energy loads in which buildings are subjected to in Mexico city, in order to provide the necessary information firstly, for planning and design of new buildings and secondly, for cost benefit analysis in the adaptation of already built structures. Solar irradiation on vertical surfaces plays a major role to determine thermal and energy performance of a building especially important for analysis of active and passive solar systems. A full year data of measurements (2014) have been compiled and analyzed. In addition, the hourly data of this horizontal and vertical measurements were compared with hourly radiation data calculated by means of two different models: the isotropic sky model (Hottel and Woertz model) and one anisotropic sky model (Perez model). The performance of the models were assessed by two common statistical parameters: the relative root mean square error (RMSE) and the mean bias error (MBE). Perez model presented better performance through the year in north, east and west façades, and the isotropic model in south façade.
\end{abstract}

Keywords: Evaluation of Models; Global Solar Irradiation, Global Vertical Irradiance, Sustainable Buildings Vertical Surfaces.

\section{Introduction}

Solar radiation data are very important to architects, engineers and scientists for energy-efficient building designs. Considering that architects work with envelopes and most of these are facades (vertical surfaces), it becomes important to measure the solar resource even more so when demand for high-rise buildings continues to increase. [1].

The lack of insolation data on vertical surfaces and improper sizing of passive insolation leads to incorrectly designed buildings. Mexico is among the sunniest countries in the world with almost $40 \%$ of its territory ( 2 million square kilometers approx.) receiving $21 \mathrm{MJ} / \mathrm{m}^{2}$ a day.[2]. Within Mexico, diffuse, direct and global irradiations on a horizontal plane are currently recorded in a varied number of locations. Nevertheless, nearly no single station exists to measure solar irradiation on vertical surfaces (north, south, east and west).

Around the world, global radiation on a horizontal surface has been measured in most meteorological stations as well and there are only a few stations which measure solar components on vertical surfaces. [3], [4].Because there are more countries without vertical stations, research on models of global vertical irradiance has been conducted. Different mathematical models [5], [6] have been developed to predict the solar irradiance on vertical surfaces from measurements on a horizontal surface. These models are mainly developed in North America and some European countries.
The benefits of studying solar radiation are several. Knowing a thermal load and its temporal distribution, the performance of certain material/technology as applied to buildings is known with more precision, before its construction. The accuracy in thermal calculations achieved by software and solar radiation predictive models would reduce overestimation of air conditioning calculations. Moreover, solar radiation is linked to natural light concept, whose correct use can save about $20-40 \%$ in office buildings. [7]. This research presents the measurements of Global solar radiation on horizontal and vertical surfaces in Mexico City and the work on testing two irradiance models on vertical surfaces based on this measured horizontal data.

\section{Method}

\subsection{Measuring Station}

A solar radiation station was installed on top of Geophysics Institute building, belonging to National Autonomous University of México (UNAM) (Latitude: 19²0' 01" North, longitude: $99^{\circ} 11^{\prime}$ 54" West, Altitude: 2268 meters above sea level ). The station is set on a clear area, free from any external obstructions and readily accessible for inspection and general cleaning. Data collection starts before sunrise and finishes after sunset.

The station consists of 5 pyranometers with a hemispherical field of view. They measure 1-min average data on horizontal and vertical surfaces $\left(90^{\circ}\right.$ on north, south, east and west façades). The 
sensors were made by Kipp and Zonen, CM11 and CMP21 models, for vertical and horizontal measurements respectively.

The sensors were duly referenced to the World Radiometric Scale. The pyranometers that measure vertical solar Irradiation were placed within a metallic structure that shades the pyranometer dome from the ground reflected radiation, so that these four radiometers have a view angle of 90 degrees and receive only the solar sky irradiance. The structure is painted black inside to minimize the effects of multiple reflections.

A Campbell data logger (CR-1000 model) was installed at the site to monitor, calculate, and store the data during the year (2014). The stored data in $\mathrm{mV}$ are converted to $\mathrm{W} / \mathrm{m}^{2}$ by means of the calibration constant of each pyranometer. The data obtained minute by minute had a quality analysis whose quality control was inspired by WMO recommendations, the BSRN (Baseline Surface Radiation Network) Recommendations, [8], [9] and from the literature [10]. Data that passed the quality control tests were converted into hourly values. To present the solar Irradiation, the data is shown in hourly, daily and monthly values $\left(\mathrm{MJ} / \mathrm{m}^{2}\right)$. For testing the irradiance models, hourly values in $\mathrm{W} / \mathrm{m}^{2}$ was used.

\subsection{Vertical Irradiance Models.}

Different models have been developed to determine the global irradiance on a vertical surface from measured horizontal data. Usually the radiation on vertical surfaces is calculated by means of decomposition models. Global horizontal radiation is decomposed, by correlations, into diffuse and beam components; starting from these data the global radiation on the vertical surfaces is reassembled as the sum of beam and diffuse solar radiation and the reflected beam from the ground and the surroundings [11].

The principal difference among the models is the treatment of the sky-diffuse component [12], [13]. Some researchers use the isotropicity of sky-diffuse component [5], [14] and others prefer to use the non-isotropicity because of the strong scattering effect of aerosols. [12], [15], [16].

Two popular sky diffuse models were selected to be analyzed and tested for their accuracy: Perez model, one of the most promising based on published results from other locations, and isotropic sky model, for being the simplest model estimator. While these two models calculate the incident sky diffuse part $\left(\mathrm{G}_{\mathrm{dv}}\right)$, the global irradiance on a vertical surface $\left(G_{v}\right)$ is the sum of the incident direct beam $\left(\mathrm{G}_{\mathrm{bv}}\right)$, incident sky diffuse $\left(\mathrm{G}_{\mathrm{dv}}\right)$ and incident groundreflected irradiances $\left(\mathrm{G}_{\mathrm{rv}}\right)$.

$\mathrm{G}_{\mathrm{v}}=\mathrm{G}_{\mathrm{bv}}+\mathrm{G}_{\mathrm{dv}}+\mathrm{G}_{\mathrm{rv}}$

Since the experimental setup was designed to avoid the ground reflected irradiance on vertical pyranometers, the equation becomes as follows:

$\mathrm{G}_{\mathrm{v}}=\mathrm{G}_{\mathrm{bv}}+\mathrm{G}_{\mathrm{dv}}$

The Louche correlation [17] was selected for estimating the beam and diffuse irradiance on horizontal surface $\left(\mathrm{G}_{\mathrm{bh}}\right.$ and $\mathrm{G}_{\mathrm{dh}}$ respectively) from global horizontal irradiance $\left(G_{h}\right)$. Direct vertical irradiance [18] is determined by the projection of the direct horizontal irradiance $\left(\mathrm{G}_{\mathrm{bh}}\right)$ onto the surface:

$\mathrm{G}_{\mathrm{bv}}=\mathrm{G}_{\mathrm{bh}} \cos \left(\theta_{\mathrm{i}}\right)$

Where $\theta_{\mathrm{i}}$ is the angle of incidence which can be easily computed from trigonometric relationships of the sun zenith and azimuth, and surface's tilt and azimuth angles. To calculate the sky diffuse component, the isotropic sky model [19] have the following equation:

$\mathrm{G}_{\mathrm{d}}=\mathrm{G}_{\mathrm{dh}} *(1+\cos \beta) * 0.5$
Where $\beta$ is the surface inclination $\left(90^{\circ}\right)$. Perez model [20] is the result of a detailed analysis of the anisotropic diffuse, circumsolar and horizon brightening irradiances that are computed by using empirically derived parameters. In this model, the sky diffuse incident irradiance is estimated by

$$
\mathrm{G}_{\mathrm{dv}}=\mathrm{G}_{\mathrm{h}}\left[\mathrm{F}_{1} \frac{\mathrm{a}}{\mathrm{b}}+\mathrm{F}_{2} \sin (\beta)+\left(1-\mathrm{F}_{1}\right) \frac{(1+\cos \beta)}{2}\right]
$$

where $a, b, F_{1}$ and $F_{2}$ are empirical parameters. $F_{1}$ and $F_{2}$ are estimated by empirical expressions as a function of two additional parameters proposed for determining the conditions of the sky clearness $(\varepsilon)$ and sky brightness $(\Delta)$.

$$
\varepsilon=\frac{\frac{\mathrm{G}_{\mathrm{dh}}+\mathrm{G}_{\mathrm{bn}}}{\mathrm{G}_{\mathrm{dh}}}+1.041 \mathrm{Z}^{3}}{1+1.041 \mathrm{Z}^{3}}
$$

$\Delta=\mathrm{m} \frac{\mathrm{G}_{\mathrm{dh}}}{\mathrm{I}_{0}}$

Where $\left(\mathrm{G}_{\mathrm{bn})}\right.$ is the direct normal irradiance $\left(\mathrm{W} / \mathrm{m}^{2}\right),(\mathrm{m})$ is the relative optical air mass and $\left(\mathrm{I}_{0}\right)$ is the direct extraterrestrial normal irradiance. The model proposes eight different categories or bins for $(\varepsilon)$ and each of these can be expressed as linear functions of $(Z)$ and $(\Delta)$ as follows:

$\mathrm{F} 1=\max [0, \mathrm{f} 11+\mathrm{f} 12 \Delta+\mathrm{f} 13 \mathrm{Z}]$

$\mathrm{F} 2=\max [0, \mathrm{f} 21+\mathrm{f} 22 \Delta+\mathrm{f} 23 \mathrm{Z}]$

The required coefficients for (f) are obtained from Perez [20]

\subsection{Evaluation of Models.}

The global component on a vertical surface was determined from the measured horizontal data using Isotropic and Perez models and compared with the measured vertical data of the same period. The comparison was conducted on an hourly basis. The accuracy of each model was assessed using statistics: MBE (Mean Bias Error), a measure of the underlying trend, and RMSE (Root Mean Square Error). In order to examine the seasonal variations, MBE and RMSE were computed by month as well as the whole year.

\section{Results and Discussion}

\subsection{Measurements}

Table 1 shows the daily mean global solar irradiation incident on horizontal $\left(\mathrm{H}_{\mathrm{g}}\right)$ and vertical surfaces North $\left(\mathrm{H}_{\mathrm{vn}}\right)$, South (Hvs), East $\left(\mathrm{H}_{\mathrm{ve}}\right)$ and West-facing $\left(\mathrm{H}_{\mathrm{vw}}\right)$.

The global irradiation on a horizontal surface $\left(\mathrm{H}_{\mathrm{g}}\right)$ presented a maximum radiation in April. The recorded daily average value for this month was $22.00 \mathrm{MJ} / \mathrm{m}^{2}$. In December, the lowest was recorded as it reached only $14.61 \mathrm{MJ} / \mathrm{m}^{2}$.

The results of global solar irradiation measured on $\mathrm{H}_{\mathrm{vn}}$, had its minimum monthly recorded value in December $\left(1.68 \mathrm{MJ} / \mathrm{m}^{2}\right)$ and the maximum in June $\left(4.23 \mathrm{MJ} / \mathrm{m}^{2}\right)$ ). The relatively short daylight period, with less solar intensity due to low value of solar declination, is in line with the results obtained in December, increasing considerably in Spring-Summer (June).

The global insolation on $\mathrm{H}_{\mathrm{ve}}$ had it lowest daily recorded value in October $\left(6.54 \mathrm{MJ} / \mathrm{m}^{2}\right)$, while the highest value was in April $(11.08$ $\mathrm{MJ} / \mathrm{m}^{2}$ ). Although similar values for the irradiation on both verti- 
cal $\mathrm{H}_{\mathrm{ve}}$ and $\mathrm{H}_{\mathrm{vw}}$ surfaces are expected, because of the geometrical symmetry between them [21], the results were different.

Table 1: The monthly mean daily global irradiation on horizontal $\left(\mathrm{H}_{\mathrm{g}}\right)$ and vertical surfaces: north $\left(\mathrm{H}_{\mathrm{vn}}\right)$, south $\left(\mathrm{H}_{\mathrm{vs}}\right)$, east $\left(\mathrm{H}_{\mathrm{ve}}\right)$ and west $\left(\mathrm{H}_{\mathrm{vw}}\right)$, in $\mathrm{MJ} / \mathrm{m}^{2}$.

\begin{tabular}{|c|c|c|c|c|c|}
\hline Month & $\mathrm{H}_{\mathrm{vn}}$ & $\mathrm{H}_{\mathrm{vs}}$ & $\mathrm{H}_{\mathrm{ve}}$ & $\mathrm{H}_{\mathrm{vw}}$ & $\mathrm{H}_{\mathrm{g}}$ \\
\hline 1 & 1.72 & 14.16 & 7.81 & 6.26 & 16.12 \\
\hline 2 & 1.75 & 14.13 & 10.06 & 7.36 & 20.34 \\
\hline 3 & 2.13 & 7.98 & 9.85 & 6.57 & 20.54 \\
\hline 4 & 2.85 & 4.95 & 11.08 & 5.76 & 22.00 \\
\hline 5 & 3.85 & 3.51 & 9.02 & 5.05 & 18.77 \\
\hline 6 & 4.23 & 3.55 & 7.07 & 5.05 & 17.45 \\
\hline 7 & 3.65 & 3.17 & 8.45 & 4.59 & 18.88 \\
\hline 8 & 3.30 & 4.23 & 9.41 & 5.30 & 19.88 \\
\hline 9 & 2.83 & 5.81 & 7.13 & 4.90 & 16.01 \\
\hline 10 & 2.21 & 8.71 & 6.54 & 5.49 & 15.74 \\
\hline 11 & 1.85 & 13.12 & 7.90 & 6.13 & 16.10 \\
\hline 12 & 1.68 & 13.49 & 6.52 & 6.06 & 14.61 \\
\hline Average & 2.67 & 8.07 & 8.40 & 5.71 & 18.04 \\
\hline
\end{tabular}

Figure 1 displays that $\mathrm{H}_{\mathrm{vw}}$ is smaller than $\mathrm{H}_{\mathrm{ve}}$ by nearly $32.02 \%$ in average, and as much as by $7.05 \%$ in December, and by 28.57 $\%$ in June. Fig. 1 also shows the global irradiation on $\mathrm{H}_{\mathrm{vs}}$. It presents a classical behavior, in that during the winter solstice, the sun is inclined towards the façade on a lower altitude, increasing the radiation on it. The maximum radiation was in winter season with $14.16 \mathrm{MJ} / \mathrm{m}^{2}$ (January), while the lowest insolation was in summer th $3.17 \mathrm{MJ} / \mathrm{m}^{2}$ (July) as the sun's altitude is high. The annual daily average irradiation on this surface was $8.07 \mathrm{MJ} / \mathrm{m}^{2}$, which is larger than in the west $\left(5.71 \mathrm{MJ} / \mathrm{m}^{2}\right)$ and north $(2.67$ $\mathrm{MJ} / \mathrm{m}^{2}$ ) façades, and definitely less than irradiation on a horizontal surface $\left(18.04 \mathrm{MJ} / \mathrm{m}^{2}\right)$.

Surprisingly the south face irradiation is not bigger than the east $\left(8.40 \mathrm{MJ} / \mathrm{m}^{2}\right)$, due to meteorological and geographic factors typical of Mexico City. The winds bring with them water vapor, cloudiness and atmospheric aerosols: Rains, heavy rain and aerosols have a great concentration in the western and southwest part of the Basin of Mexico, mainly in the second part of the day, attenuating the radiation measurements in the west façade.

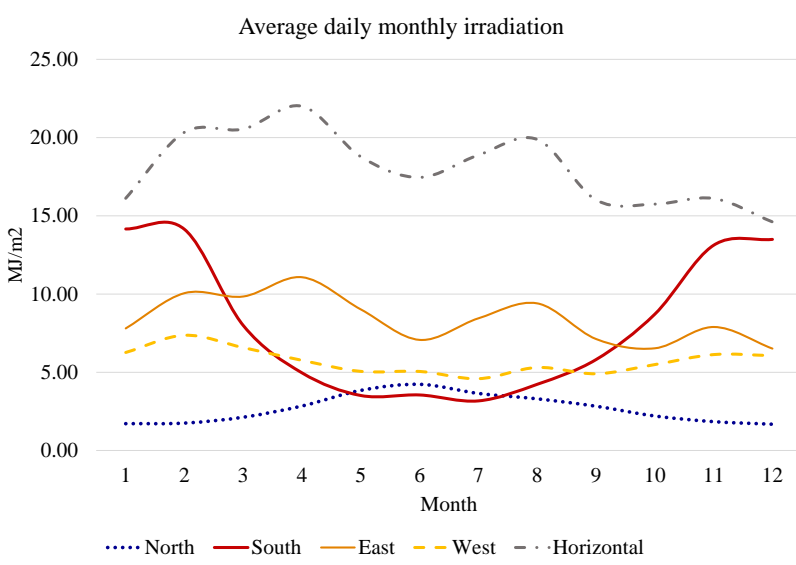

Fig. 1: The monthly average daily global irradiation on horizontal $\left(\mathrm{H}_{\mathrm{g}}\right)$ and vertical surfaces: south $\left(\mathrm{H}_{\mathrm{vs}}\right)$, north $\left(\mathrm{H}_{\mathrm{vn}}\right)$, east $\left(\mathrm{H}_{\mathrm{ve}}\right)$ and west $\left(\mathrm{H}_{\mathrm{vw}}\right)$, in $\mathrm{MJ} / \mathrm{m}^{2}$.

To obtain more detailed information of the radiation distribution on the façades, three-dimensional heat maps are obtained and presented in figure 2. The graph displays the solar energy received from 5:00 a.m. to 8:00 p.m. for the whole month in vertical and horizontal surfaces in winter (January) and summer (July), the months with lower and higher radiation recorded on the south façade. Here the opposite behaviour of the horizontal and vertical planes are clearly shown: whereas in summer the horizontal plane receives the highest irradiation, the southern surface receives it in winter.
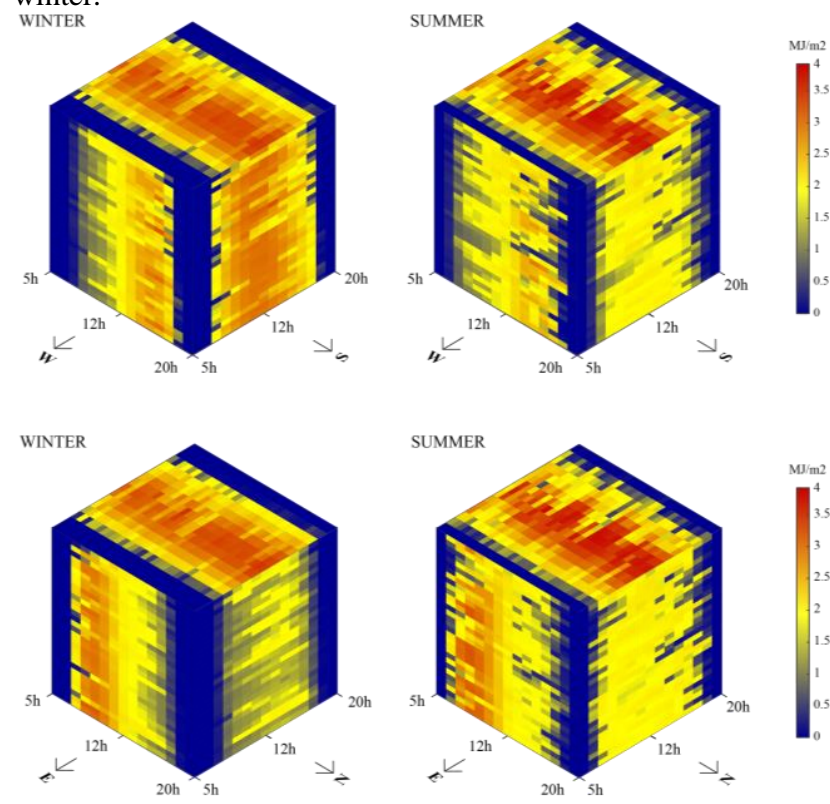

Fig. 2: Graphics of the solar behavior in the architectural envelope in summer and winter season.

\subsection{Tested Models}

Tables 2 to 5 show the MBE and RMSE results of each model for each of the twelve months and for the whole year at the four cardinal orientations. It can be observed from the tables that lowest and highest RMSE values occur in February for both Perez and Isotropic models respectively; Perez's model, ranging from 15.43 $\mathrm{W} / \mathrm{m} 2$ in February for the north facing to $60.32 \mathrm{~W} / \mathrm{m}^{2}$ in March for the south facing. Isotropic model ranges from $21.40 \mathrm{~W} / \mathrm{m}^{2}$ in October for south facing to $89.48 \mathrm{~W} / \mathrm{m} 2$ in February for east facing.

For each model, the RMSE values in $\mathrm{W} / \mathrm{m}^{2}$ for all vertical surfaces did not differ a great deal. Nevertheless, in terms of percentage, north facing surface has the highest RMSE value and this can be explained by the fact that this surface received basically solar diffuse component of low measured mean value. The isotropic model had the worst performance but not too different from Perez's model results.

The lowest underestimate MBE values happened in March for both Isotropic and Perez models, the highest over estimate MBE values happened in February for both Isotropic and Perez model as well. Results ranged from an underestimation of $-41.27 \mathrm{~W} / \mathrm{m}^{2}$ in March for the south surface to an overestimation of $44.97 \mathrm{~W} / \mathrm{m}^{2}$ in February for the east surface. For the whole year, the MBE ranges from $-22.67 \mathrm{~W} / \mathrm{m}^{2}$ for the north facing to $9.91 \mathrm{~W} / \mathrm{m}^{2}$ on the east surface.

Table 2: Summary of MBE and RMSE for vertical global irradiance (North-facing surface).

\begin{tabular}{|c|c|c|c|c|c|c|c|c|c|c|c|c|c|}
\hline Model & Jan & Feb & Mar & Apr & May & Jun & Jul & Aug & Sep & Oct & Nov & Dec & Annual \\
\hline \multicolumn{14}{|c|}{ Isotropic $\left(\mathrm{W} / \mathrm{m}^{2}\right)$} \\
\hline MBE & -30.09 & -22.44 & -32.71 & -15.69 & -14.68 & -23.71 & -16.79 & -15.54 & -24.18 & -27.88 & -25.68 & -26.19 & -22.67 \\
\hline
\end{tabular}




\begin{tabular}{|l|c|c|c|c|c|c|c|c|c|c|c|c|c|}
\hline MBE\% & -63.71 & -50.60 & -61.53 & -22.47 & -17.41 & -26.07 & -21.17 & -19.69 & -33.91 & -49.58 & -51.01 & -58.40 & -34.59 \\
\hline RMSE & 37.89 & 29.46 & 45.83 & 32.12 & 34.21 & 35.73 & 32.39 & 35.85 & 39.00 & 37.85 & 34.24 & 33.35 & 35.87 \\
\hline RMSE\% & 80.22 & 66.43 & 86.21 & 45.99 & 40.55 & 39.30 & 40.84 & 45.43 & 54.68 & 67.30 & 68.01 & 74.34 & 54.73 \\
\hline Perez $\left(\mathrm{W} / \mathrm{m}^{2}\right)$ & \\
\hline MBE & -15.46 & -10.34 & -10.68 & 5.82 & 3.69 & -8.26 & -0.44 & 7.68 & 3.12 & -7.28 & -10.99 & -13.60 & -4.37 \\
\hline MBE\% & -32.73 & -23.32 & -20.09 & 8.34 & 4.38 & -9.09 & -0.55 & 9.73 & 4.37 & -12.94 & -21.83 & -30.33 & -6.67 \\
\hline RMSE & 21.11 & 15.43 & 21.02 & 24.60 & 34.53 & 29.46 & 29.36 & 34.72 & 23.27 & 17.65 & 17.87 & 18.24 & 25.27 \\
\hline RMSE\% & 44.70 & 34.79 & 39.54 & 35.23 & 40.94 & 32.39 & 37.02 & 44.01 & 32.62 & 31.38 & 35.50 & 40.65 & 38.54 \\
\hline
\end{tabular}

Table 3: Summary of MBE and RMSE for vertical global irradiance (South-facing surface).

\begin{tabular}{|c|c|c|c|c|c|c|c|c|c|c|c|c|c|}
\hline Model & Jan & Feb & Mar & Apr & May & Jun & Jul & Aug & Sep & Oct & Nov & Dec & Annual \\
\hline \multicolumn{14}{|c|}{ Isotropic $\left(\mathrm{W} / \mathrm{m}^{2}\right)$} \\
\hline MBE & 28.88 & 17.60 & -33.04 & -23.52 & -11.10 & -10.27 & -10.19 & -16.26 & -16.05 & -2.83 & 16.17 & 25.95 & -3.89 \\
\hline MBE\% & 7.44 & 4.92 & -16.40 & -19.32 & -14.44 & -13.50 & -14.82 & -16.00 & -10.98 & -1.28 & 4.51 & 7.21 & -1.98 \\
\hline RMSE\% & 12.21 & 8.19 & 26.91 & 27.71 & 41.94 & 43.22 & 47.98 & 30.32 & 17.14 & 9.70 & 9.06 & 11.74 & 18.06 \\
\hline \multicolumn{14}{|c|}{ Perez $\left(\mathrm{W} / \mathrm{m}^{2}\right)$} \\
\hline MBE & -14.84 & -12.99 & -41.27 & -11.21 & 12.36 & 15.27 & 12.78 & 2.99 & -11.41 & -18.02 & -23.77 & -17.27 & -7.79 \\
\hline MBE\% & -3.82 & -3.63 & -20.49 & -9.21 & 16.08 & 20.06 & 18.58 & 2.94 & -7.80 & -8.17 & -6.63 & -4.80 & -3.96 \\
\hline RMSE & 41.45 & 29.65 & 60.32 & 27.84 & 34.36 & 34.94 & 35.75 & 25.64 & 24.81 & 29.87 & 39.29 & 37.33 & 36.20 \\
\hline RMSE\% & 10.67 & 8.29 & 29.94 & 22.87 & 44.71 & 45.90 & 51.98 & 25.22 & 16.97 & 13.54 & 10.95 & 10.37 & 18.41 \\
\hline
\end{tabular}

Results with Perez model range from an underestimation of 41.27 $\mathrm{W} / \mathrm{m}^{2}$ in March for the south façade to an overestimation of 30.27 $\mathrm{W} / \mathrm{m}^{2}$ in February for the east façade. Annually, Perez's model tends to underestimate the solar irradiance for north, south and west vertical surfaces by no less than $-6.67 \%$ and to overestimate the east vertical surface by no more than $2.35 \%$. Perez's model most accurately predicts the vertical irradiance for the north facing surface if the solar irradiance received consists of diffuse component only or includes just a small portion of direct component when the solar altitude is high. For east and west facades, Perez's model presents better results in most of the months; in the east surface, overestimation by Perez's model was in September and underestimation in May and July. On west façade, Perez's model underestimation was between October and March, especially in January, February, November and December.

For the south façade, Isotropic model presented more accuracy having less under estimation compared with Perez model. The annual average RMSE and MBE values for all vertical surfaces are $30.08 \%$ and $-7.05 \%$ respectively.

Table 4: Summary of MBE and RMSE for vertical global irradiance (East-facing surface)

\begin{tabular}{|c|c|c|c|c|c|c|c|c|c|c|c|c|c|}
\hline Model & Jan & Feb & Mar & Apr & May & Jun & Jul & Aug & Sep & Oct & Nov & Dec & Annual \\
\hline \multicolumn{14}{|c|}{ Isotropic $\left(\mathrm{W} / \mathrm{m}^{2}\right)$} \\
\hline MBE & 23.21 & 44.97 & 8.28 & 17.05 & -0.01 & -10.00 & -4.31 & 5.35 & 0.50 & 3.72 & 24.34 & 19.19 & 9.91 \\
\hline MBE\% & 11.14 & 17.55 & 3.31 & 6.33 & 0.00 & -6.56 & -2.34 & 2.40 & 0.28 & 2.25 & 11.11 & 10.98 & 4.83 \\
\hline RMSE\% & 37.35 & 34.91 & 32.30 & 23.62 & 23.57 & 26.46 & 25.24 & 22.26 & 24.37 & 32.96 & 29.81 & 32.88 & 29.52 \\
\hline \multicolumn{14}{|l|}{ Perez } \\
\hline MBE & 17.19 & 30.27 & -2.69 & 8.51 & -4.30 & -8.00 & -7.06 & 2.14 & 3.69 & 2.94 & 14.13 & 11.22 & 4.81 \\
\hline MBE\% & 8.25 & 11.81 & -1.08 & 3.16 & -2.18 & -5.26 & -3.84 & 0.96 & 2.06 & 1.78 & 6.45 & 6.42 & 2.35 \\
\hline RMSE & 53.72 & 57.26 & 51.07 & 35.33 & 40.43 & 44.64 & 42.00 & 39.05 & 37.66 & 41.44 & 40.19 & 34.58 & 43.48 \\
\hline RMSE\% & 25.78 & 22.34 & 20.41 & 13.12 & 20.55 & 29.31 & 22.84 & 17.51 & 21.09 & 25.10 & 18.35 & 19.79 & 21.19 \\
\hline
\end{tabular}

Table 5: Summary of MBE and RMSE for vertical global irradiance (West-facing surface).

\begin{tabular}{|c|c|c|c|c|c|c|c|c|c|c|c|c|c|}
\hline Model & Jan & Feb & Mar & Apr & May & Jun & Jul & Aug & Sep & Oct & Nov & Dec & Annual \\
\hline \multicolumn{14}{|c|}{ Isotropic $\left(\mathrm{W} / \mathrm{m}^{2}\right)$} \\
\hline $\mathrm{MBE}$ & -0.90 & -6.53 & -16.75 & -11.36 & -12.63 & -15.49 & -11.19 & -15.16 & -17.11 & -12.03 & -8.75 & -6.58 & -11.43 \\
\hline MBE\% & -0.52 & -3.54 & -10.41 & -8.10 & -11.41 & -14.29 & -11.23 & -11.93 & -13.90 & -8.62 & -5.46 & -4.15 & -8.26 \\
\hline RMSE\% & 26.63 & 27.72 & 34.85 & 23.82 & 30.68 & 32.47 & 34.66 & 34.49 & 32.50 & 28.24 & 22.76 & 24.59 & 29.68 \\
\hline \multicolumn{14}{|c|}{ Perez $\left(\mathrm{W} / \mathrm{m}^{2}\right)$} \\
\hline MBE & -16.03 & -22.33 & -18.97 & -8.76 & -3.42 & -4.31 & -0.93 & -8.30 & -8.01 & -13.55 & -18.58 & -18.70 & -11.27 \\
\hline MBE\% & -9.24 & -12.12 & -11.79 & -6.25 & -3.09 & -3.98 & -0.93 & -6.53 & -6.51 & -9.72 & -11.60 & -11.78 & -8.15 \\
\hline RMSE & 45.89 & 56.11 & 47.68 & 38.76 & 36.92 & 37.66 & 33.80 & 52.58 & 38.25 & 37.63 & 38.01 & 40.04 & 42.20 \\
\hline RMSE\% & 26.45 & 30.44 & 29.63 & 27.64 & 33.37 & 34.75 & 33.93 & 41.38 & 31.08 & 26.98 & 23.73 & 25.22 & 30.51 \\
\hline
\end{tabular}

\subsection{Photovoltaic Potential in Buildings}

The irradiation data obtained in this work permits more accurate estimation of the photovoltaic (PV) production in Mexico City, considering PV modules integrated in the different vertical building façades. The integration of photovoltaic systems in buildings (BIPV) is one of the most interesting application to improve the efficiency of buildings and to include renewable energy sources for electrical generation in the cities. The final yield of the façades depends on the orientation. Considering a typical performance ratio of 0.75 for BIPV systems, the annual productivity of the east façade is $639 \mathrm{kWh} / \mathrm{kWp}$, slightly higher than the south's $(613 \mathrm{kWh} / \mathrm{kWp})$ and $48 \%$ higher than the west's $(432 \mathrm{kWh} / \mathrm{kWp})$, where Wp means watts-peak, and refers to the power in watts of the PV generator installed. These figures allow the calculation of the annual photovoltaic energy produced by a building façade in Mexico City, as a function of the PV power installed. The assessment of the BIPV potential of an area of the city, would need a previous analysis of the suitable envelope area of each building to install PV modules [22] using GIS (Geographic Information System) tools com- 
bined with aerial photogrammetric data and local descriptive information [23], [24].

\section{Conclusion}

The one year (2014) measurement and analysis of Global Solar Irradiation in horizontal $\left(\mathrm{H}_{\mathrm{g}}\right)$ and vertical surfaces north $\left(\mathrm{H}_{\mathrm{vn}}\right.$, south $\left(\mathrm{H}_{\mathrm{vs}}\right)$, east $\left(\mathrm{H}_{\mathrm{ve}}\right)$ and west $\left(\mathrm{H}_{\mathrm{vw})}\right.$ in Mexico City, together with an evaluation of predicted global vertical irradiance based on two vertical surface models (Isotropic and Perez) was conducted. The recorded data showed normal pattern. The anomalies were the non-symmetrical shape of vertical west and east global solar irradiation $\left(\mathrm{H}_{\mathrm{vw}}\right.$ and $\left.\mathrm{H}_{\mathrm{ve}}\right)$ where $\mathrm{H}_{\mathrm{vw}}$ was found smaller than $\mathrm{H}_{\mathrm{ve}}$ and the south face is not bigger than East in the annual daily average, due to the effects of clouds, wind, rain and aerosols. Taking the horizontal irradiation as a reference, the south and the east surface received practically half of the horizontal surface $(44.73 \%$ and $46.58 \%$, respectively), while the west receives one third (31.66\%) and the north one seventh $(14.80 \%)$.

The results obtained were compared with other countries data listed in the literature [25][26] having similar latitude to Mexico City $\left(19^{\circ} 20^{\prime} 01^{\prime \prime} \mathrm{N}, \mathrm{H}_{\mathrm{g}}=18.04 \mathrm{MJ} / \mathrm{m}^{2}\right)$, such as Puerto Rico, San Juan $\left(18.4^{\circ} \mathrm{N}, \mathrm{H}_{\mathrm{g}}=18.61 \mathrm{MJ} / \mathrm{m}^{2}\right)$, Hawaii, Honolulu $\left(21.3^{\circ} \mathrm{N}, \mathrm{H}_{\mathrm{g}}=18.60 \mathrm{MJ}^{2} \mathrm{~m}^{2}\right)$, and Bahrain $\left(26^{\circ} \mathrm{N}, \mathrm{H}_{\mathrm{g}}=22.5\right.$ $\mathrm{MJ} / \mathrm{m}^{2}$ ), being consistent with all of them, taking into consideration the latitude, sea level and sky quality differences.

In the analysis of models, Perez model presented better performance through the year in north, east and west facades, having similar results with the isotropic model in summer season and getting better results in winter season. For the south surface, Isotropic model shows more accuracy. It has been observed that high RMSE and MBE percentage values were found in north facing surface, which receives basically diffuse irradiation.

Models at the south, east and west facing surface increase they accuracy when the solar irradiance includes a high portion of direct component. There is a consistent trend for both Perez and Isotropic model to under estimate the values, particularly when the vertical surface receives more diffuse solar irradiance. The high solar radiation of Mexico City as it is located within the "solar belt", being one of the places with greater solar radiation on the planet, takes relevant importance since it forces designers to think about the use of envelope materials because of the load that is received. Design and sizing of BIPV benefit also form this more accurate knowledge of the solar irradiation of the building's different surfaces. Preceded by good results, this studies in cities of intertropical zones can be replicated.

The climatic conditions of the sites are determining factors for the irradiation distribution in different building surfaces in time and space. For this reason, the indiscriminate use of calculation models without being tested with real site measurements, can lead to false conclusions about solar resource knowledge.

Measurements and adapted calculation models are both tools that help architects and engineers to build more efficient and friendly buildings, with lower energy costs in maintenance, returning to a fundamental element of design by the knowledge of climatic environment.

\section{Acknowledgement}

The authors would like to thank the National Council of Science and Technology (CONACYT) for the scholarship awarded and for supporting the development of this work; the team of the solar radiation section of Geophysics Institute of UNAM for the experimental data used; Leonardo B. Zeevaert Alcántara and Ricardo Sánchez B. (General Direction of buildings and conservation, DGOC, UNAM) for the support in publication process.

\section{References}

[1] Li, D. and Lam, J. (2000). Vertical solar radiation and daylight illuminance data for Hong Kong. Lighting Research and Technology, 32(2), 93-98.

[2] Galindo, E. I., Cifuentes, N. G., \& Universidad Nacional Autónoma de México. (1996). Irradiación solar global en la República Mexicana: Valores, horarios medios. México: UNAM, Programa Universitario de Energia. Coordinación de la Investigación Científica, Universidad Nacional Autónoma de México.

[3] Loutzenhiser, P., Manz, H., Felsmann, C., Strachan, P., Frank, T. and Maxwell, G. (2007). Empirical validation of models to compute solar irradiance on inclined surfaces for building energy simulation. Solar Energy, 81(2), 254-267.

[4] Muneer, T. and Angus, R. (1993). Daylight illuminance models for the United Kingdom. Lighting Research and Technology, 25(3), 113-123.

[5] Liu, B.Y.H. y Jordan, R.C. (1961). Daily insolation on surfaces tilted toward the equator. ASHRAE J. 3(10), 53-59.

[6] Perez, R., Ineichen, P., Seals, R., Michalsky, J. and Stewart, R. (1990) Modeling Daylight Availability and Irradiance Components from Direct and Global Irradiance. Solar Energy, 44, $271-$ 289.

[7] Muneer, T., Gueymard, C., Kambezidis, H., \& Muneer, T. (2004). Solar radiation and daylight models: (with software available from companion web site). Oxford: Elsevier Butterworth Heinemann.

[8] McArthur, L.B.J. (2004). Baseline Surface Radiation Network (BSRN): Operations Manual (Version 2.1). Climate Research.

[9] A., R., M., W., A., O., E. G., D., C. N., L., \& T., Z. (2011) Assessment of BSRN radiation records for the computation of monthly means. Atmospheric Measurement Techniques, Vol 4 , Iss $2, \mathrm{Pp} 339-354$

[10] Li, D., Lam, J. and Lau, C. (2002). A new approach for predicting vertical global solar irradiance. Renewable Energy, 25(4), pp.591-606

[11] Cucumo, M., Marinelli, V. and Oliveti, G. (1994). Ingegneria solare. Bologna: Pitagora editrice.

[12] Muneer, T. (1990). Solar radiation model for Europe. Building Services Engineering Research and Technology, 11(4), 153-163.

[13] Abdelrahman, M., \& Elhadidy, M. (1986). Comparison of calculated and measured values of total radiation on tilted surfaces in Dhahran, Saudi Arabia. Solar Energy, 37(3), 239-243.

[14] Koronakis, P. (1986). On the choice of the angle of tilt for south facing solar collectors in the Athens basin area. Solar Energy, 36(3), 217-225.

[15] Perez, R., Seals, R., Ineichen, P., Stewart, R. and Menicucci, D. (1987). A new simplified version of the perez diffuse irradiance model for tilted surfaces. Solar Energy, 39(3),221-231.

[16] Gueymard, C. (1987). An anisotropic solar irradiance model for tilted surfaces and its comparison with selected engineering algorithms. Solar Energy, 38(5), 367-386.

[17] Louche, A., Notton, G., Poggi, P. and Simonnot, G. (1991). Correlations for direct normal and global horizontal irradiation on a French Mediterranean site. Solar Energy, 46(4), pp.261266.

[18] Gueymard, C. (1987). An anisotropic solar irradiance model for tilted surfaces and its comparison with selected engineering algorithms. Solar Energy, 38(5), 367-386.

[19] HC, Hottel \& BB, Woertz. (1942). Performance of flat-plate solar-heat collectors. Trans. ASME (Am. Soc. Mech. Eng.); (United States), 64, 91

[20] Perez, R., Ineichen, P., Seals, R., Michalsky, J. and Stewart, R. (1990). Modeling daylight availability and irradiance components from direct and global irradiance. Solar Energy, 44(5), 271-289.

[21] Robledo L., Soler A. (2003), Energy Conversion Manage, 44 (15), 2455-2469.

[22] Martin Chivelet, Nuria. (2016). Photovoltaic potential and landuse estimation methodology. Energy. 94. 233-242.

[23] Caamaño-Martín, Estefanía \& Higueras Garcia, Ester \& Neila, Javier \& Useros, I \& Masa-Bote, D \& Tortora, Fiorella \& Díaz- 
Palacios, S \& Marrero, X \& Alonso, A \& Saade, A \& Jedliczka, M \& Miquel, C \& de l'Epine, M \& Willdbrett, E \& Kjellsson, E \& Cornander, A \& Fernandes, J. (2012). Solar potential calculation at city and district levels. WIT Transactions on Ecology and the Environment. 155, 675-685.

[24] Verso, A \& Martín Avila, Ana María \& Amador Guerra, Julio \& Dominguez, Javier. (2015). GIS-based method to evaluate the photovoltaic potential in the urban environments: The particular case of Miraflores de la Sierra. Solar Energy. 117. 236-245.

[25] Duffie, J. and Beckman, W. (2013). Solar engineering of thermal processes. Hoboken, N.J.: Wiley.

[26] Muneer, T., Alnaser, W. and Fairooz, F. (2007). The insolation on vertical surface having different directions in the Kingdom of Bahrain. Desalination, 209(1-3), 269-274. 